\title{
Sjögren syndrome and neuromyelitis optica spectrum disorder co-exist in a common autoimmune milieu
}

\author{
Síndrome de Sjögren e espectro da neuromielite óptica coexistem em meio de autoimunidade \\ Diogo C. Carvalho, Tauana S. Tironi, Denise S. Freitas, Rodrigo Kleinpaul, Natalia C. Talim, Marco A. Lana-Peixoto
}

\begin{abstract}
The relationship between Sjögren's syndrome (SS) and neuromyelitis optica spectrum disorder (NMOSD) is not completely understood. We report two patients with both conditions and review 47 other previously reported cases meeting currently accepted diagnostic criteria, from 17 articles extracted from PubMed. Out of 44 patients whose gender was informed, 42 were females. Mean age at onset of neurological manifestation was 36.2 years (10-74). Serum anti-AQP4-IgG was positive in 32 patients, borderline in 1, and negative in 4. Our Case 1 was seronegative for AQP4-IgG and had no non-organ-specific autoantibodies other than anti-SSB antibodies. Our Case 2 had serum anti-AQP4, anti-SSA/SSB, anti-thyreoglobulin and anti-acethylcholine-receptor antibodies, as well as clinical hypothyreoidism, but no evidence of myasthenia gravis. Our Cases and others, as previously reported in literature, with similar heterogeneous autoimmune response to aquaporin-4, suggest that SS and NMO co-exist in a common autoimmune milieu which is not dependent on aquaporin-4 autoimmunity.
\end{abstract}

Keywords: neuromyelitis optica spectrum disorders, neuromyelitis optica, Sjögren's syndrome, autoimmunity, AQP4-IgG.

\begin{abstract}
RESUMO
A relação entre síndrome de Sjögren (SS) e espectro da neuromielite óptica (ENMO) ainda não é bem compreendida. Relatamos dois pacientes com ambas as condições e revisamos 47 casos que preenchem critérios diagnósticos das duas doenças, descritos em 17 artigos extraídos da PubMed. Dos 44 pacientes cujo gênero foi informado 42 eram mulheres. A idade média ao início das manifestações neurológicas foi 36,2 anos (10-74). O anticorpo anti-AQP4 foi positivo em 32 dos 37 pacientes, em 1 foi "borderline". Nosso Caso 1 era soronegativo para AQP4-IgG, não tinha autoanticorpos não-órgão específicos, exceto anti-SSB. 0 Caso 2 era soropositivo para anticorpos anti-AQP4, anti-SSA/SSB, anti-tireoglobulina, e anti-receptor da acetilcolina; apresentava hipotireoidismo, mas não havia evidêncas de miastenia gravis. Nossos casos e outros similares, previamente relatados na literatura, com resposta autoimune heterogênea à aquaporina-4 sugerem que a SS e o ENMO coexistem em meio de autoimunidade não dependente da aquaporina-4.
\end{abstract}

Palavras-chave: espectro de neuromielite óptica, neuromielite óptica, síndrome de Sjögren, autoimunidade, AQP4-lgG.

Neuromyelitis optica (NMO) is an immune-mediated inflammatory disorder of the central nervous system in which the optic nerves and spinal cord are predominantly involved ${ }^{1,2}$. The term "NMO spectrum disorder" (NMOSD) was coined theyear following the publication of the revised criteria for diagnosis of the disease ${ }^{3}$ to include anti-aquaporin 4 seropositive patients with limited forms of the disease - either longitudinally extensive transverse myelitis (LETM) or bilaterally simultaneous or recurrent optic neuritis; patients with established NMO and cerebral, diencephalic and brainstem MRI lesions; those with co-existing systemic autoimmune diseases; and finally those with the diagnosis of Asian type multiple sclerosis (MS) or opticospinal $\mathrm{MS}^{4}$.
Although it has long been known that a number of neurologic complications may occur in association with systemic autoimmune disorders, most frequently systemic lupus erythematosus (SLE) and Sjögren's syndrome (SS) ${ }^{5,6}$, the relationship between them and NMOSD remains to be fully established. The high prevalence of a variety of autoimmune disorders and non-organ-specific autoantibodies in the serum of NMOSD patients suggests that these patients harbor a genetic predisposition to a diffuse autoimmune abnormality with multiple serological and symptomatic expression. On the other hand, this hypothesis supports the diagnosis of NMOSD in patients with SS or SLE who present LETM and/or bilateral or recurrent 
optic neuritis associated or not with anti-AQP4 serum positive status ${ }^{7}$.

Herein we present two illustrative cases of patients with primary SS and definite NMO with opposite AQP4-IgG serostatus and different serological pattern of non-organ-specific autoantibodies to demonstrate that these conditions co-exist in a common autoimmune milieu. We also review the main demographic and clinical features of patients with this association whose cases have been previously reported.

\section{OBJECTIVE}

This study aims to demonstrate that SS and NMOSD coexist in a common milieu of autoimmunity irrespective of patients' AQP4-IgG serostatus and presence of non-organ specific autoantibodies. Two representative cases with opposite AQP4-IgG serostatus and different serum nonorgan specific autoantibodies patterns are presented. A review of the previously reported cases of NMOSD associated with SS is used to support the proposition.

\section{METHOD}

We report two patients with the association of primary SS and NMO, examined at CIEM Multiple Sclerosis Research Center of the Federal University of Minas Gerais Medical School, in Belo Horizonte, Brazil, who exhibited opposite AQP4-IgG serostatus and a different profile of serum nonorgan-specific autoantibodies. Additionally, we searched the PubMed database up to December 2013 for case reports on the association of SS and NMOSD. The search was limited to reports in English language. Selected keywords used were Sjögren's syndrome, systemic rheumatic disease, systemic autoimmune disease, myelitis, neuromyelitis optica, neuromyelitis optica spectrum disorder, recurrent optic neuritis, and Devic's disease. In addition, the reference sections of the extracted articles were searched. We only extracted case reports of patients who met both the diagnostic criteria for SS as recommended by the American-European Consensus Group $^{8}$ (Table 1), and the revised diagnostic criteria for $\mathrm{NMO}^{3}$ (Table 2), or the limited forms of NMO within the $\mathrm{NMOSD}^{4}$. The Institutional Ethical Committee of the Federal University of Minas Gerais approved this study.

\section{RESULTS}

\section{Case 1}

A 44-year-old white woman was diagnosed as having SS due to a prolonged course of arthralgia, adynamia and a childhood complaint of sicca syndrome which had never
Table 1. American-European Consensus criteria for Sjögren's syndrome*.

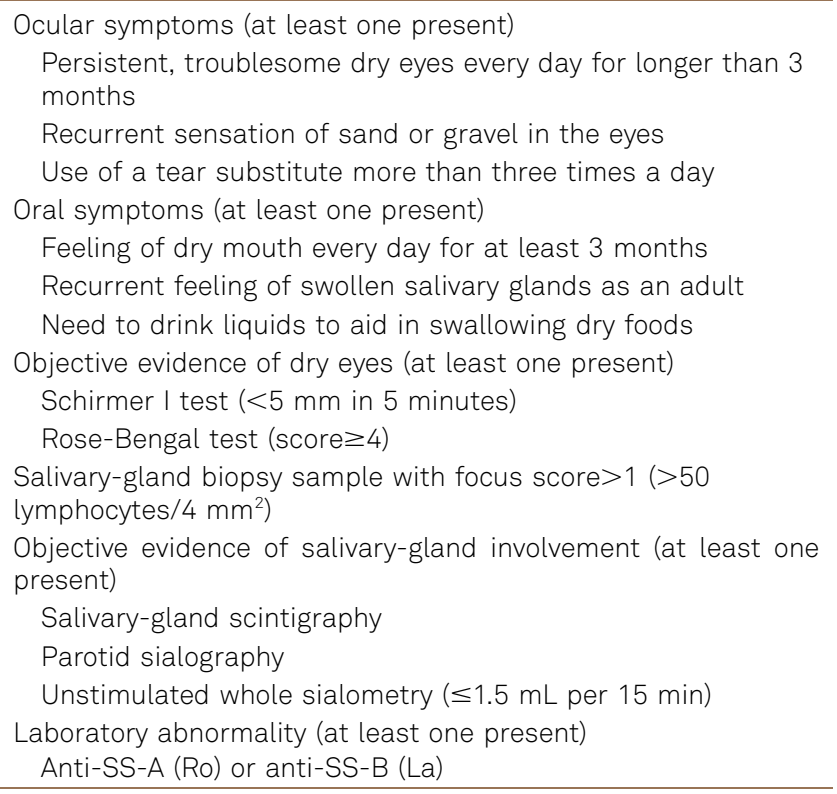

*Diagnosis of primary Sjögren's syndrome requires 4 of 6 criteria, including either positive biopsy of salivary gland or serology ${ }^{8}$.

Table 2. Revised criteria for diagnosis of neuromyelitis optica*

Absolute criteria

Optic neuritis

Acute myelitis

Supportive criteria

Normal brain MRI at disease onset, or not meeting diagnostic criteria for MS

Spinal cord MRI with T2 signal abnormality extending over three or more vertebral segments NMO-IgG (AQP4-IgG) seropositive status

*Diagnosis of definite NMO requires 2 absolute criteria plus at least 2 of 3 supportive criteria ${ }^{3}$.

been appropriately investigated. She was put on a threemonth course of prednisone $40 \mathrm{mg}$ daily with a significant relief of symptoms. Two months later, she was hospitalized because of gait disturbance and frequent falls. Cervical and thoracic spinal MRI showed a T2-weighted hyperintensive lesion extending from T2 to T7 levels (Figure 1). Brain MRI disclosed a T2-weighted hyperintensive lesion in the midbrain, and a few nonspecific supratentorial white matter small patches. The patient was treated with intravenous methylprednisolone for five days, followed by oral steroids for four months with complete recovery. One month following steroids withdrawal, she developed bilateral visual loss, paraparesis, sensation loss caudal to T10 level, and sphincter dysfunction. She was given another course of intravenous methylprednisolone for three days followed by oral prednisone and azathioprine. On a follow-up visit, visual acuity was 20/100 OU, the optic discs were pale, and there were moderate paraparesis and decreased sensation caudal to T10. The EDSS was 6.0. Laboratory work-up showed positive anti-SSB and ruled out other autoimmune, hematological 


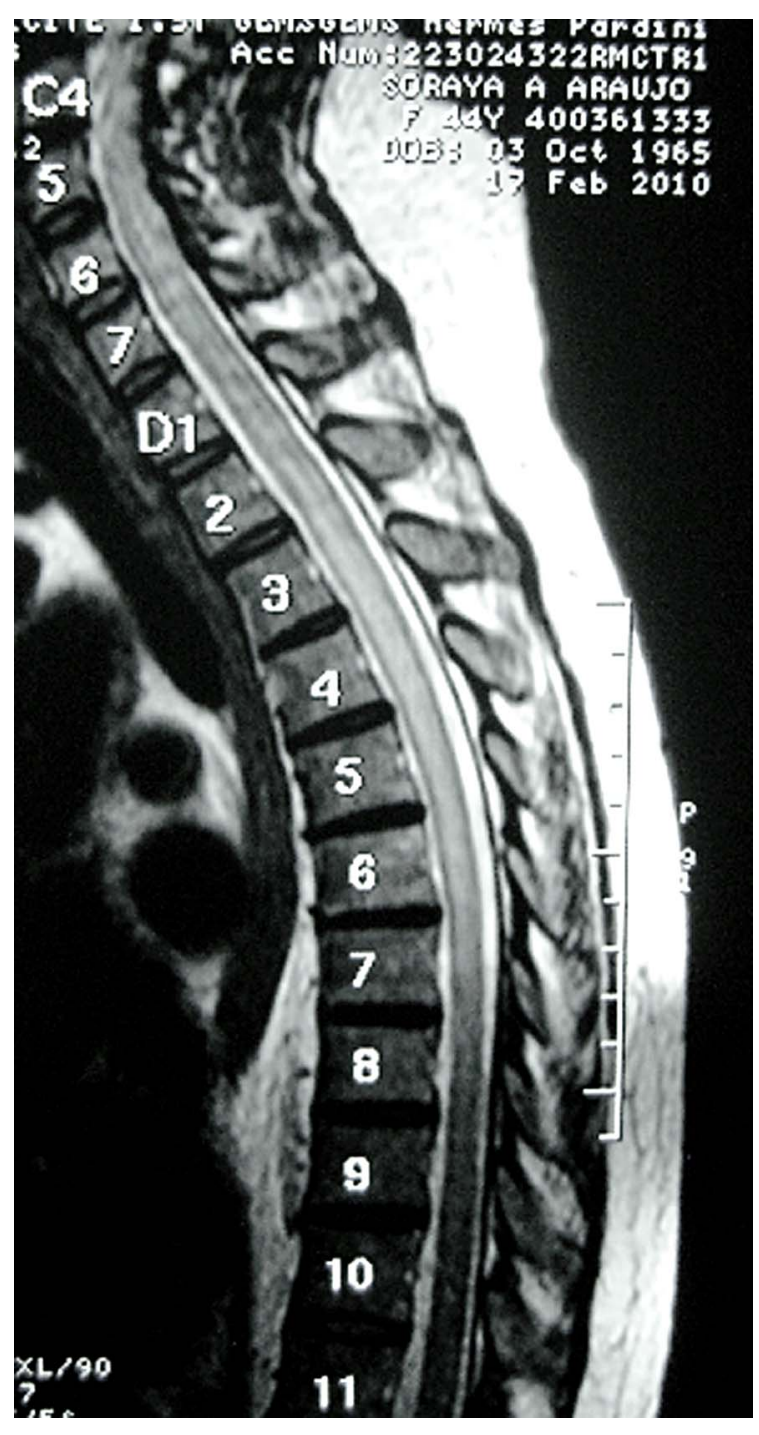

Figure 1. Case 1.MRI of cervical and thoracic spinal cord showing T2-weighted hypeintensive tumefactive lesion extending from T2 to T7 levels.

and infectious disorders. Cell-based assay for serum AQP4IgG was negative. Minor salivary glands biopsy showed dilated ducts and a moderate inflammatory infiltrate of mononuclear cells.

\section{Case 2}

A 45-year-old Bolivian female was referred to our Center because of recurrent attacks of optic neuritis. She had had four previous attacks since the age of 22 with full recovery of vision following treatment with intravenous methylprednisolone. Since her late twenties she had sicca syndrome, and at 30 she was diagnosed with SS. The visual acuity was 20/30, right eye, and 20/50, left eye. There were a left relative afferent pupillary defect, and a mild impairment of color vision in the left eye. On ophthalmoscopy there was bilateral mild pallor of the optic discs. Humphrey's perimetry revealed a superior arcuate defect in the right eye, and a central scotoma involving the temporal hemifield in the left

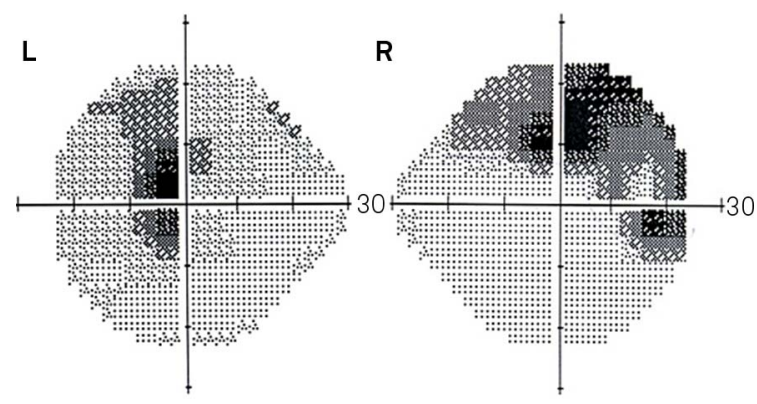

Figure 2. Case 2. Humphrey perimetry. Right eye: superior arcuate defect. Left eye: central scotoma involving the temporal hemifield.

eye (Figure 2). The remaining of the examination was unrevealing. Work-up disclosed serum anti-SSA, anti-SSB, ANA, anti-thyreoglobulin and anti-acethylcholine receptor antibodies. Serum AQP4-IgG was also positive. Cerebrospinal fluid analysis was unrevealing. Brain MRI showed a hyperintensive signal with gadolinium enhancement on the left optic nerve, and a small dot in the right frontal cortex with no enhancement. Both Schirmer's and Rose Bengal tests yielded positive results. Salivary gland scintigraphy showed delayed excretion of tracer. The patient was treated with oral prednisone. One year later she developed Lhemitte's symptom, dysesthesia in both lower limbs and a sensation level below T10. Spinal MRI showed a contrast-enhanced lesion in $\mathrm{C} 2$ and a T2-weighted tumefactive lesion extending from T4 to T10. The patient was given a new course of intravenous methylprednisolone with full recovery and was then put on mycophenolate mofetil.

Our search disclosed 17 previously published articles which are individual case reports or small series of patients with the association of SS and NMOSD ${ }^{9,10,11,12,13,14,15,16,17,18,19,20,21,22,23,24}$. Adding our two patients, a total of 49 patients could be found harboring the association of both diseases according to current accepted diagnostic criteria (Table 3$)^{3,4,8}$. However, some overlapping may have occurred in the series reported by Kim et al. ${ }^{16}$ and Min et al. ${ }^{17}$ Information about gender was available on 44 patients (42 females) whereas the mean age at onset of the neurologic symptoms was 36.2 years (10-74). Both optic neuritis and transverse myelitis were observed in 27 patients, whereas in 13 patients there was just one clinical event, either optic neuritis or transverse myelitis, in association with AQP4-IgG seropositive status. In 9 cases the authors did not inform whether patients had full or limited NMO. Information about the inaugural manifestation of the association was provided for 15 patients. In 8 of them the neurologic symptoms preceded the sicca symptoms, 4 had sicca symptoms preceding the neurological manifestations, whereas in 3 the NMOSD and SS symptoms occurred simultaneously.

Brain symptoms, mainly related to brainstem involvement were observed in 16 patients. The patient described by Asai et al. ${ }^{21}$ developed left hemiparesis and hypoesthesia 


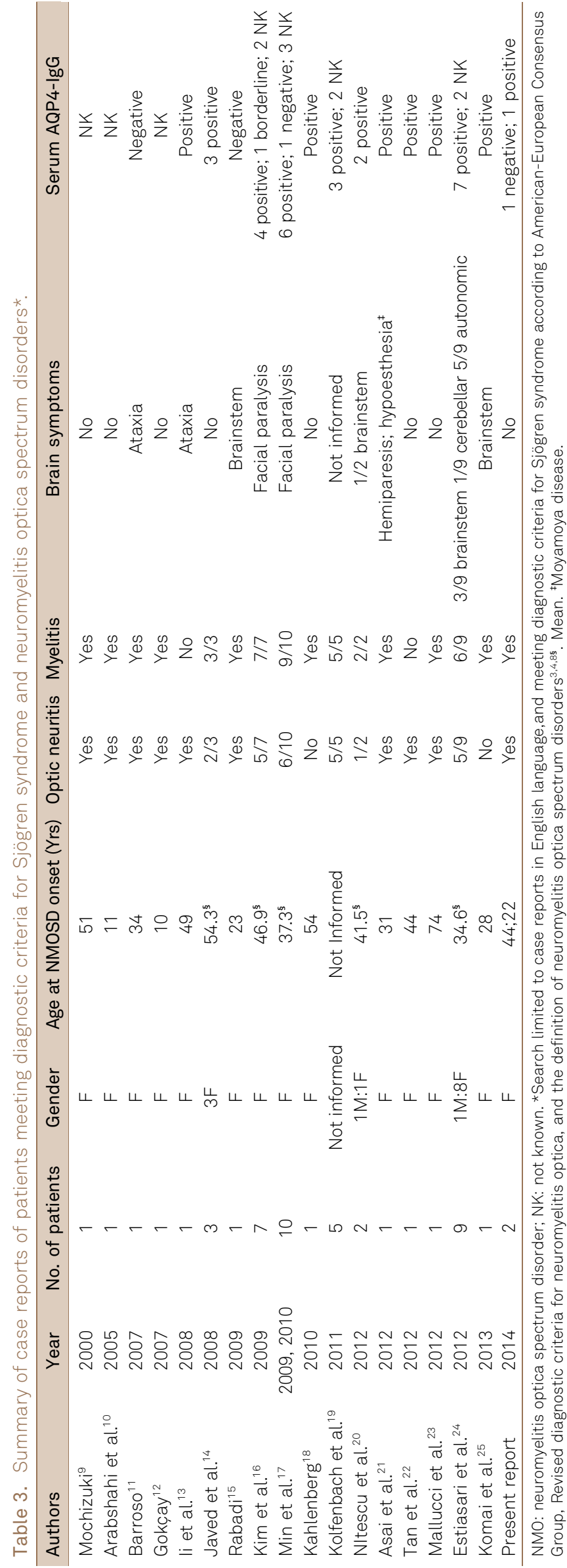

as a result of right thalamic hemorrhage which occurred in association with Moyamoya disease. Out of 37 patients whose AQP4-IgG serostatus was informed it was positive in 32 , negative in 4 and "borderline" in 1.

\section{DISCUSSION}

Although isolated transverse myelitis, optic neuritis, and full NMO have long been known to occur in association with $\mathrm{SS}^{7,26}$ the frequency of this association, and the relationship between these conditions remain to be better understood. The widely variable reported prevalence of SS in NMO patients of $2-30 \%^{1,27}$ most probably results from the use of different criteria for diagnosis of these conditions.

In this review we exclusively selected case reports or small series whose patients had met the American-European Consensus Group criteria for diagnosis of SS and the revised criteria for diagnosis of NMO, or the limited forms of NMO associated with AQP4-IgG seropositivity, as we aimed to assure that all patients had both SS and NMOSD.

The vast majority of patients harboring this association presented AQP4-IgG seropositive status suggesting a high intensity of inflammatory disease activity. It has been demonstrated that patients with AQP4-IgG seropositive status have higher titles of ant-SSA/SSB antibodies, more acute course of SS, and higher prevalence of other associated autoimmune disorders ${ }^{17,24}$.

It is probable that many other AQP4-IgG seropositive patients with LETM or optic neuritis in association with sicca symptoms reported in the literature, but not yet fulfilling the International Consensus criteria for SS may have developed serum anti-SSA and anti-SSB antibodies later in the course of their disease. It has been shown that only about one fifth of patients with primary SS and neurologic manifestations have anti-SSA or anti-SSB antibodies at diagnosis, and this delay may lead to an underestimation of the prevalence of SS in patients with NMOSD ${ }^{18}$.

An additional reason for the scanty number of cases fulfilling the diagnostic criteria for both conditions may be the variable sensitivity of the current essays for serum AQP4-IgG determination. Currently available assays include a tissuebased indirect immunofluorescence (IIF) assay; ELISA; fluorescence immunoprecipitation assay (FIPA); fluorescenceactivated cell sorting (FACS) assay; and visual fluorescence-observation cell-based assay (CBA). A recent international comparative study of the different techniques to detect AQP4-IgG in sera of patients with NMO and NMOSD showed that although their specificities were excellent their sensitivities were variable ${ }^{28}$. Whereas the most sensitive techniques were human AQP4-transfected cell-based assays (73\%-77\%), fluorescence immunoprecipitation assay (FIPA) and the mouse tissue-based indirect immunofluorescence 
assay were the least sensitive (around 50\%). The commercially introduced ELISA which is a simple and relatively sensitive technique may make AQP4-IgG serum assessment more widely available. However, a group of $20 \%-30 \%$ of NMO patients remain seronegative for the antibody even by the use of the most sensitive assay available.

In addition to insufficient assay sensitivity, frequent causes for seronegative status include remission of the disease, use of immunosuppressive agents and apheresis. It is probable that NMO is a heterogeneous syndrome with different physiopathogenetic mechanisms. The group of NMO seronegative patients shows no female preponderance, and higher proportion of Caucasians, monophasic course, simultaneous optic neuritis and transverse myelitis ${ }^{29}$.

Recently we have identified antibodies to myelin oligodendrocyte glycoprotein (MOG) in a group of patients with AQP4-IgG seronegative NMOSD. Although seropositive anti-MOG patients represent only $7 \%$ of all NMOSD cases they are important for their phenotypical differences as compared to AQP4-IgG seropositive patients which include preponderance of males, more frequency of optic nerve than spinal cord involvement, more frequency of monophasic course, and a better functional recovery after an $\operatorname{attack}^{30}$.

Our Case 1 had sicca syndrome long before developing NMO. This patient and some previously reported cases ${ }^{11,15,17}$ are examples of AQP4-IgG seronegative status in patients with SS and NMO. Notwithstanding their seronegative status might have resulted from essay insufficient sensitivity, disease remission, or treatment, these patients may be true AQP4-IgG seronegative NMO cases, and their disease related to MOG antibodies or other unidentified antibodies. Whereas the hypothesis of cross reaction between aquaporin-4 - predominantly expressed in the optic nerves and spinal cord - and aquaporin-5 - highly expressed in the salivary glands - may explain the coincidence of inflammatory attacks in the CNS and salivary glands in seropositive patients, as these antigens share about $50 \%$ of their protein sequence $^{14}$, the relationship between SS and AQP4-IgG seronegative patients remains unclear.

On the other hand, Case 2 developed recurring optic neuritis few years before the manifestations of SS. She showed a marked predisposition to develop multiple serum autoantibodies. In addition to show AQP4-IgG seropositive status, she had serum anti-SSA/SSB, anti-tireoglobulin (associated with clinical hypothyroidism), and anti-acethylcholine-receptor antibodies (not associated with clinical symptoms of myasthenia gravis).

Our cases and the present review of the previously reported patients with the association of SS and NMOSD corroborate the current evidences which suggest the presence of an autoimmune milieu, most probably defined by genetic factors, favoring the co-existence of both conditions. They also demonstrate that NMOSD occurring in association with SS is not directly dependent on AQP4 autoimmunity, although AQP4-IgG positive serostatus is found in the great majority of patients with full manifestations of SS and NMOSD. Further research is necessary to elucidate determinant elements which trigger the onset and the phenotypical manifestations of both diseases.

\section{Acknowledgments}

The authors thank Prof. Kazuo Fujihara and Dr. Douglas K. Sato for help with the AQP4-IgG cell-based assays performed at Tohoku University, Sendai, Japan, and Dr. Dagoberto Callegaro for review of the manuscript.

\section{References}

1. Wingerchuk DM, Hogancamp WF, O'Brien PC, Weinshenker BG. The clinical course of neuromyelitisoptica (Devic's syndrome). Neurology 1999;53:1107-1114.

2. Lana-Peixoto MA. Devic'sneuromyelitisoptica: a critical review. ArqNeuropsiquiatr 2008;66:120-138.

3. Wingerchuk DM, Lennon VA, Pittock SJ, Lucchinetti CF, Weinshenker BG. Revised diagnostic criteria for nueromyelitisoptica . Neurology 2006;66:1485-1489.

4. Wingerchuk DM, Lennon VA, Lucchinetti CF, Pittock SJ, Weinshenker BG. The spectrum of neuromyelitisoptica. Lancet Neurol 2007;6:805-815.

5. Dubois EL, Tuffanelli DL. Clinical manifestations of systemic lupus erythematosus. Computer analysis of 520 cases. JAMA 1964;190:104-111.

6. Alexander GE, Provost TT, Stevens MB, Alexander EL. Sjögren syndrome: Central nervous system manifestations. Neurology 1981;31:1391-1396.

7. Wingerchuk DM, Weinshenker BG. The emerging relationship between neuromyelitisoptica and systemic rheumatologic autoimmune disease. MSJ 2012;18:5-10.
8. Vitali C, Bombardieri S, Jonsson R, et al. Classification criteria for Sjögren's syndrome: a revised version of the European criteria proposed by the American-European Consensus Group. Ann Rheum Dis 2002;61:554-558.

9. Mochizuki A, Hayashi A, Hisahara S, Shoji S. Steroid-responsive Devic's variant in Sjögren's syndrome. Neurology 2000;54:1391-1392.

10. Arabshahi B, Pollock AN, Sherry DD, Albert DA, Kreiger PA, Pessler F Devic disease in a child with primary Sjögren syndrome. J Child Neurol 2006;21:285-286.

11. Barroso B. Primary Sjögren's syndrome mimicking neuromyelitisoptica. Eur J Intern Med 2007;18:507.

12. Gökçay F, Çelebisoy N, Gökçay A, Kabasakal Y, Öder G. Primary Sjögren's syndrome presenting as neuromyelitisoptica. Pediatr Neurol 2007;36:58-60.

13. Ii Y, Shindo A, Sasaki R, Naito Y, Tanaka K, Kuzuhara S. Reversible stenosis of large cerebral arteries in a patient with combined Sjögren's syndrome and neuromyelitisoptica spectrum disorder. Rheumatol Int 2008;28:1277-1280. 
14. Javed A, Balabanov R, Arnason BGW, et al. Minor salivary gland inflammation in Devic's disease and longitudinally extensive myelitis. Mult Scler 2008;14:809-814.

15. Rabadi $\mathrm{MH}$, Kundi S, Brett D, Padmanabhan R. Primary Sjögren syndrome presenting as neuromyelitisoptica. J Neurol Neurosurg Psychiatry 2010;8:213-214.

16. Kim SM, Waters P, Vincent A, et al. Sjögren's syndrome myelopathy: spinal cord involvement in Sjögren's syndrome might be a manifestation of neuromyelitisoptica. Mult Scler 2009;15:1062-1068.

17. Min JH, Kim SH, Park MS, Kim BJ, Lee KH. Brain MRI lesions characteristic of neuromyelitisoptica and positive anti-aquaporin 4-antibody may predict longitudinal extensive myelitis and optic neuritis in Sjögren's syndrome. Mult Scler 2010;16:762-764.

18. Kahlenberg JM. Neuromyelitisoptica spectrum disorder as an inicial presentation of primary Sjögren's syndrome. Semin Arthritis Rheum 2011;40:343-348.

19. Kolfenbach JR, Horner BJ, Ferucci ED, West SG. Neuromyelitisoptica spectrum disorder in patients with connective tissue disease and myelitis. Arthritis Care Res 2011;63:1203-1208.

20. Nitescu D, Nicolau A, Caraiola S, Predeteanu D, Ionescu R, Tanasescu C. Neuromyelitisoptica-complication or comorbidity in primary Sjogre's syndrome? Rom J Intern Med 2011;49:295-300.

21. Asai Y, Nakayasu H, Fusayasu E, Nakashima K. Moyamoya disease presenting as thalamic hemorrhage in a patient with neuromyelitisoptica and Sjögren's syndrome. J Stroke Cerebrovasc Dis 2012;21:617-619.

22. Tan P, Yu WY, Umapathi T, Lim SA. Severe optic neuritis in a patient with combined neuromyelitisoptica spectrum disease and primary Sjögren's syndrome: a case report. J Med Case Rep 2012;6:401-404.

23. Mallucci G, Franciotta D, Romani A, Ceroni M, Bergamaschi R. Antiaquaporin-4 antibody-positive recurrent isolated optic neuritis and primary Sjögren's syndrome. J Neurol 2012;259:1740-1741.

24. Estiasari R, Matsushita T, Masaki K. Comparison of clinical, immunological and neuroimaging features between anti-aquaporin4 antibody-positive and antibody-negative Sjögren's syndrome patients with central nervous system manifestations. Mult Scler 2012;18:807-816.

25. Komai T, Shoda H, Yamaguchi K, et al. Neuromyelitis optica spectrum disorder complicated with Sjögren syndrome successfully treated with tocilizumab: a case report. Mod Rheumatol 2014. [Epub ahead of print DOI: 10.3109/08916934.2014.883501]

26. Pittock SJ, Lennon VA, de Seze J, et al. Neuromyelitis optica and nonorgan specific autoimmunity. Arch Neurol 2008;65:78-83.

27. deSeze J, Stojkovic T, Ferriby D, et al. Devic'sneuromyelitis optica: clinical, laboratory, MRI and outcome profile. J Neurol Sci 2002;197:57-61.

28. Waters PJ, McKeon A, Leite MI, et al. Serologic diagnosis of NMO: a multicenter comparison of aquaporin-4-lgG assays. Neurology 2012;78:665-671.

29. Marignier R, Bernard-Valnet R, Giraudon P, et al. Aquaporin-4 antibody-negative neuromyelitis optica: distinct assay sensitivitydependent entity. Neurology 2013;80:2194-2200.

30. Sato DK, Callegaro D, Lana-Peixoto MA, et al. Distinction between MOG antibody-positive and AQP4 antibody positive NMO spectrum disorders. Neurology 2014;82:474-481. 